\title{
Mixed oligopoly and the choice of capacity
}

\author{
Yuanzhu Lu, Sougata Poddar* \\ Department Of Economics, National University of Singapore (NUS), AS2 Level 6, Arts Link, \\ Singapore 117570, Singapore
}

Received 27 July 2004; received in revised form 29 August 2005; accepted 15 September 2005

\begin{abstract}
We analyze the capacity choice of firms under different time structures in a mixed oligopoly market, in which firms decide not only production quantities but also capacity scales. We show that the public firm never chooses excess capacity, while the private firm never chooses under capacity under all possible strategic environments.

(C) 2005 University of Venice. Published by Elsevier Ltd. All rights reserved.

JEL classification: L13; D43

Keywords: Public firm; Private firm; Excess capacity; Under capacity
\end{abstract}

\section{Introduction}

Mixed oligopolies are common in many countries. Oil industries, heavy manufacturing industries, telecommunications or tourism industry are good examples of mixed oligopolies. In a typical situation of mixed oligopoly, where at least one firm is public (non-profit maximizer) and competing with private firms, the main focus of the study in the literature so far was to see welfare implications as the number of firms changes in the industry (see Cremer et al., 1989; De Fraja and Delbono, 1990; Nett, 1993; Anderson et al., 1997). Very few models have focused on the impact of sequential choice of capacity and quantity (or price) by the competing firms on the outcomes in a mixed oligopoly environment. In contrast, in the literature of oligopoly the issue of choosing over (excess) capacity or under capacity from a strategic point of view by the competing firms in

\footnotetext{
* Corresponding author. Fax: +65 67752646.
}

E-mail address: ecssp@nus.edu.sg (S. Poddar).

1090-9443/\$ - see front matter (c) 2005 University of Venice. Published by Elsevier Ltd. All rights reserved. doi:10.1016/j.rie.2005.09.004 
a sequential game of 'capacity then quantity' has always been a matter of central concern. There exists an extensive literature addressing this issue under private oligopoly framework (i.e. when all firms are private, i.e. pure profit maximizers) Spence (1977); Dixit (1980), Saloner (1985), Tirole (1988); Basu and Singh (1990) and among many others. However, not many studies on this issue have been done in the framework of a mixed oligopoly where the same question is equally applicable. In this paper, we would like to fill up that gap in the literature. ${ }^{1}$ The results regarding excess or under capacity in a private oligopoly framework varies widely and it very much depends on modeling environment; for example see Dixit (1980); Bulow et al. (1985) for conflicting results. In view to that here we would like to find out how the outcomes in a mixed oligopoly framework stand in comparison to those findings under private oligopoly.

We analyze the capacity choice of firms under different time structures in a mixed oligopoly market, in which firms decide not only production quantities but also capacity levels. For simplicity, we assume there is one public firm and one private firm. The public firm maximizes social surplus (welfare), whereas the private firm maximizes its own profit. We consider a three-stage game of four different time structures. In the first two time structures, capacities are chosen sequentially (alternatively by the public and the private firm), and then quantities are chosen simultaneously, where as in the last two time structures, capacities are chosen simultaneously, and the quantities are chosen sequentially (alternatively by the public and the private firm). Under these time structures, we show that the public firm never chooses excess capacity, while the private firm never chooses under capacity under all possible strategic environments. These results complement the findings of a private oligopoly model and distinguish the role of a public firm when it competes with a profit maximizing private firm.

\section{Model}

We consider a mixed duopoly market. Two firms are operating in a homogeneous good market where the inverse demand is given by

$$
p=a-Q=a-\left(q_{a}+q_{b}\right), \quad a>0
$$

where $p$ is market price, $Q$ is total output and $q_{i}$ denotes the output of firm $i(=a, b)$. Firm $a$ is a profit-maximizing private firm, and firm $b$ is a public firm maximizing the social surplus (welfare) which is the summation of the consumer surplus and the firms' profits.

The firms have different technologies, represented by the cost function, $C_{i}\left(q_{i}, x_{i}\right)$, where $q_{i}$ and $x_{i}$ are the production quantity and capacity of firm $i$, respectively.

For simplicity, following Vives (1986); Horiba and Tsutsui (2000); Nishimori and Ogawa (2004), we specify the cost function as

$$
C_{i}\left(q_{i}, x_{i}\right)=m_{i} q_{i}+\left(q_{i}-x_{i}\right)^{2} .
$$

\footnotetext{
${ }^{1}$ Very recent work along this line is done by Nishimori and Ogawa (2004), and previously in the context of entry by Ware (1986). The game with endogenous timing of choosing quantities in a mixed oligopoly was studied by Pal (1998).
} 
This cost function clearly shows the advantage of well-coordinated capacity-quantity choice. Excess capacity or under capacity would result in inefficiency. Under this U-shaped cost function, the long-run average cost is actually minimized when quantity equals production capacity, i.e. $q_{i}=x_{i}$. One can contrast this type of cost structure with the type of cost structure which is more frequently observed in the literature addressing sequential capacity and quantity choice in oligopoly models. ${ }^{2}$ In the literature, more often production beyond planned capacity is considered to be extra costly than production within the capacity-limit chosen before. Although holding idle capacity is itself costly, but in most cases cost of having excess capacity and under capacity is not considered exactly symmetry. Here, we assume a cost structure where the cost of having excess or under capacity is symmetric.

We assume $m_{a}<m_{b}$; that is, firm $a$ can produce more efficiently than firm $b$ at the efficient production-capacity level. ${ }^{3}$ We also assume $a-m_{b} \geq(830 / 247)\left(m_{b}-m_{a}\right)$ such that capacities and quantities are non-negative in all the cases we consider.

The objective function of firm $a$ is given by

$$
\pi_{a}=p q_{a}-m_{a} q_{a}-\left(q_{a}-x_{a}\right)^{2}
$$

and firm $b$ maximizes the social surplus described by

$$
\mathrm{SS}=\frac{Q^{2}}{2}+\pi_{a}+\pi_{b}
$$

where $Q^{2} / 2$ is the consumer surplus.

\subsection{The different time structures}

We consider firms' choice of capacity in the following three-stage games:

Case 1: The public firm $b$ chooses capacity first, then the private firm $a$ chooses capacity, and in the third stage both firms choose quantity simultaneously.

Case 2: The private firm $a$ chooses capacity first, then the public firm $b$ chooses capacity, and in the third stage both firms choose quantity simultaneously.

Case 3: Both firms choose capacity simultaneously in the first stage, then the public firm $b$ chooses quantity in the second stage, and the private firm $a$ chooses quantity in the third stage.

Case 4: Both firms choose capacity simultaneously in the first stage, then the private firm $a$ chooses quantity in the second stage, and the public firm $b$ chooses quantity in the third stage.

\footnotetext{
${ }^{2}$ The more frequently used cost function (or a variant of it) in the literature is: $C_{i}\left(q_{i}, x_{i}\right)=\left(m_{i}+w_{i}\right) x_{i}+\left(m_{i}+\right.$ $\left.w_{i}+\Delta m_{i}\right)\left(q_{i}-x_{i}\right)=\left(m_{i}+w_{i}\right) q_{i}+\Delta m_{i}\left(q_{i}-x_{i}\right)$ if $q_{i}>x_{i}, C_{i}\left(q_{i}, x_{i}\right)=m_{i} q_{i}+w_{i} x_{i}$ if $q_{i} \leq x_{i}$ where $w_{i}$ marginal cost of capacity and $\Delta m_{i}$ is the extra cost of producing the output beyond the planned capacity.

${ }^{3}$ Note that $m_{a} \geq m_{b}$ will yield zero profit for the private firm.
} 


\section{Equilibrium analysis}

We look for subgame perfect Nash equilibrium of each of the sequential game.

Case 1. Following the standard equilibrium concept, we solve the model from the third stage.

Given their production capacities, the maximization problem of each firm yields

$$
\begin{aligned}
& q_{a}=\frac{a-m_{a}+2 x_{a}-q_{b}}{4}, \\
& q_{b}=\frac{a-m_{b}+2 x_{b}-q_{a}}{3} .
\end{aligned}
$$

By solving (5) and (6), we obtain the output levels as follows:

$$
\begin{aligned}
& q_{a}=\frac{2 a-3 m_{a}+m_{b}+6 x_{a}-2 x_{b}}{11}, \\
& q_{b}=\frac{3 a+m_{a}-4 m_{b}-2 x_{a}+8 x_{b}}{11} .
\end{aligned}
$$

In the second stage, firm $a$ takes their quantity level in the third stage into account and wants to maximize its profit by choosing its capacity. It takes the capacity chosen by firm $b$ in stage one as given.

$$
\max _{x_{a}} \pi_{a}=\left(a-q_{a}-q_{b}\right) q_{a}-m_{a} q_{a}-\left(q_{a}-x_{a}\right)^{2}
$$

s.t. (7) and (8).

Solving the problem, we have

$$
x_{a}=\frac{12}{49}\left(2 a-3 m_{a}+m_{b}-2 x_{b}\right)
$$

Substituting (9) into (7) and (8), we get

$$
\begin{aligned}
& q_{a}=\frac{11}{49}\left(2 a-3 m_{a}+m_{b}-2 x_{b}\right), \\
& q_{b}=\frac{1}{49}\left(9 a+11 m_{a}-20 m_{b}+40 x_{b}\right) .
\end{aligned}
$$

In the first stage, firm $b$ knows that its decision regarding the capacity level affects firm $a$ 's capacity decision in the second stage and their output decisions in the third stage. Thus, 
its maximization problem can be formulated as

$$
\begin{aligned}
\max _{x_{b}} \mathrm{SS}= & \frac{\left(q_{a}+q_{b}\right)^{2}}{2}+\left(a-q_{a}-q_{b}\right) q_{a}-m_{a} q_{a}-\left(q_{a}-x_{a}\right)^{2}+\left(a-q_{a}-q_{b}\right) q_{b} \\
& -m_{b} q_{b}-\left(q_{b}-x_{b}\right)^{2}
\end{aligned}
$$

s.t. (9), (10) and (11).

Solving the problem, we have

$$
x_{b}=a-m_{b}-\frac{830}{247}\left(m_{b}-m_{a}\right) .
$$

Substituting (12) into (9), (10) and (11) gives us

$$
\begin{aligned}
& x_{a}=\frac{588}{247}\left(m_{b}-m_{a}\right), \\
& q_{a}=\frac{539}{247}\left(m_{b}-m_{a}\right), \\
& q_{b}=a-m_{b}-\frac{733}{247}\left(m_{b}-m_{a}\right) .
\end{aligned}
$$

Now, comparing (13) with (14) and (12) with (15) we get the following proposition.

Proposition 1. In the three-stage game in which public firm chooses its capacity before the private firm's choice of capacity and then both choose quantity simultaneously, the private firm chooses excess capacity, while the public firm chooses under capacity.

To maximize the social surplus, it is desirable for a public firm to have total outputs provided by the private firm since the private firm is more efficient. This implies that the public firm tries to make the private firm produce more while it produces less. Since capacity is strategic substitute and there is a positive relationship between the capacity level of private firm and its output level, the public firm can improve the social surplus by reducing its own capacity so that the private firm increases its capacity and quantity. On the other hand, enlarging the production share in the market is desirable for the private firm. Hence, the private firm ends up choosing excess capacity while the public firm chooses under capacity. ${ }^{4}$

Case 2. Following the same procedure, we can get (7) and (8) again. Then in the second stage, the public firm chooses capacity to maximize social surplus:

\footnotetext{
${ }^{4}$ The result is very similar to the key result in Nishimori and Ogawa (2004).
} 


$$
\begin{aligned}
\max _{x_{b}} \mathrm{SS}= & \frac{\left(q_{a}+q_{b}\right)^{2}}{2}+\left(a-q_{a}-q_{b}\right) q_{a}-m_{a} q_{a}-\left(q_{a}-x_{a}\right)^{2}+\left(a-q_{a}-q_{b}\right) q_{b} \\
& -m_{b} q_{b}-\left(q_{b}-x_{b}\right)^{2}
\end{aligned}
$$

s.t. (7) and (8).

If there is interior solution, then we can get the public firm's reaction function:

$$
x_{b}=a-m_{b}-\frac{14}{31}\left(m_{b}-m_{a}+2 x_{a}\right) .
$$

Substituting (16) into (7) and (8) yields

$$
\begin{aligned}
& q_{a}=\frac{11}{31}\left(m_{b}-m_{a}+2 x_{a}\right), \\
& q_{b}=a-m_{b}-\frac{13}{31}\left(m_{b}-m_{a}+2 x_{a}\right) .
\end{aligned}
$$

And in the first stage, the private firm's profit maximization problem is:

$$
\max _{x_{a}} \pi_{a}=\left(a-q_{a}-q_{b}\right) q_{a}-m_{a} q_{a}-\left(q_{a}-x_{a}\right)^{2}
$$

s.t. (16), (17) and (18).

We can find that

$$
\frac{\partial \pi_{a}}{\partial x_{a}}=\frac{1}{961}\left[968\left(m_{b}-m_{a}\right)+14 x_{a}\right]>0 .
$$

It means that the larger the private firm's capacity is, the more its profit. Hence, the private firm will choose capacity large enough so that the public firm will choose no capacity, $x_{b}=0$. To make the public firm choose no capacity, the private firm's capacity has to satisfy the following constraint (follows from (16)):

$$
x_{a} \geq \frac{1}{28}\left(31 a-45 m_{b}+14 m_{a}\right) \text {. }
$$

To derive the private firm's optimal capacity level, we substitute $x_{b}=0$ into (7) and (8) and get

$$
\begin{aligned}
& q_{a}=\frac{1}{11}\left(2 a+m_{b}-3 m_{a}+6 x_{a}\right), \\
& q_{b}=\frac{1}{11}\left(3 a-4 m_{b}+m_{a}-2 x_{a}\right) .
\end{aligned}
$$

In the first stage, the private firm maximizes its profit subject to (19), (20) and (21). It is easy to get the solution:

$$
x_{a}=\frac{1}{28}\left(31 a-45 m_{b}+14 m_{a}\right) .
$$


It follows that

$$
\begin{aligned}
q_{a} & =\frac{11}{14}\left(a-m_{b}\right), \\
q_{b} & =\frac{1}{14}\left(a-m_{b}\right) .
\end{aligned}
$$

Thus, we have the following proposition:

Proposition 2. In the three-stage game in which the private firm chooses its capacity before the public firm's choice of capacity and then both choose quantity simultaneously, the public firm chooses no capacity and produces positive quantity, while the private firm chooses excess capacity.

The result is similar to that in Case 1. The difference is that the public firm chooses no capacity, which is reasonable. Because the public firm chooses its capacity after the private firm makes it choice of capacity and since it (the public firm) always tries to make the private firm produce more while it produces less, it ends up choosing no capacity.

Case 3. Following the same procedure of backward induction as in Case 1, we can get the following results:

$$
\begin{aligned}
& x_{a}=\frac{192}{89}\left(m_{b}-m_{a}\right), \\
& x_{b}=a-m_{b}-\frac{215}{89}\left(m_{b}-m_{a}\right), \\
& q_{a}=\frac{172}{89}\left(m_{b}-m_{a}\right), \\
& q_{b}=a-m_{b}-\frac{215}{89}\left(m_{b}-m_{a}\right) .
\end{aligned}
$$

Thus, Proposition 3 follows:

Proposition 3. In the three-stage game in which both firms choose capacity simultaneously in the first stage, and then the public firm chooses quantity followed by the private firm, the public firm chooses exact capacity while the private firm chooses excess capacity.

The economic intuition of this result is different from the previous ones. First of all, since both firms choose capacity simultaneously there is no commitment advantage in the first stage; and as a result, unlike previous cases, there is no leadership advantage while choosing capacities. But due to strategic reason, i.e. to have a larger share of 
output in the future quantity market, both firms behave aggressively at that stage in choosing their capacities. ${ }^{5}$ However, this opens up the possibility of ending up with excess capacity later in the quantity choosing stage. Now, the firm moving in stage two (in this case the public firm) can adjust its choice of quantity (using limited leadership advantage) so that it does not end up in costly excess capacity. But, the firm moving in the third stage (in this case the private firm) being a follower has to take the quantity choice of the leader as given and produce (constrained) optimal quantity in response to that. Naturally, this does not match with its previous capacity choice. Now, because of higher capacity choice in the first stage (due to the aggressive behavior), it eventually ends up with excess capacity.

Case 4. In this case, we have the following results:

$$
\begin{aligned}
& x_{a}=\frac{15}{8}\left(m_{b}-m_{a}\right), \\
& x_{b}=a-m_{b}-\frac{9}{4}\left(m_{b}-m_{a}\right) . \\
& q_{a}=\frac{15}{8}\left(m_{b}-m_{a}\right), \\
& q_{b}=a-m_{b}-\frac{17}{8}\left(m_{b}-m_{a}\right) .
\end{aligned}
$$

Thus, Proposition 4 follows:

Proposition 4. In the three-stage game in which both firms choose capacity simultaneously in the first stage, and then the private firm chooses quantity followed by the public firm, public firm chooses under capacity, while private firm chooses exact capacity.

Here, the intuition is similar to the previous proposition up to a point. It is the same up until the second stage of the game. But since the objective of the public firm is different from the private firm, the end result gets different in the third stage. Since the objective of the public firm is welfare maximization (as opposed to profit), despite being a follower at stage three, its best response quantity still exceeds its initial capacity choice.

\section{Choice of excess capacity or under capacity}

We summarize firms' choice of capacity into Table 1.

This leads us to the main result of our analysis.

\footnotetext{
${ }^{5}$ Note that in case of quantity competition firms' profits are increasing in their own quantities; moreover, quantities are strategic substitutes. Hence, the aggressive behavior arises in the capacity choice stage.
} 
Table 1

Choice of capacity under different time structures

\begin{tabular}{lll}
\hline Case & Public firm & Private firm \\
\hline 1 & Under capacity & Excess capacity \\
2 & Under capacity, no capacity & Excess capacity \\
3 & Exact capacity & Excess capacity \\
4 & Under capacity & Exact capacity \\
\hline
\end{tabular}

Theorem. In games under mixed oligopoly where capacities and quantities are chosen sequentially, the public firm never chooses excess capacity, while the private firm never chooses under capacity in the equilibrium.

If both firms move simultaneously in the capacity choice stage, neither has commitment advantage; then the leader firm in the quantity choice stage uses its limited leadership advantage to choose quantity which is exactly equal to its capacity scale. This results in exact capacity choice for the second stage leader. In all the other cases, the private firm chooses excess capacity while the public chooses under capacity. The economic intuition is that the profit-maximizing private firm wants to build over capacity so that it can produce more, which is what the public firm hopes since the private firm is more efficient and as a consequence to this the public firm ends up choosing under capacity.

\section{Concluding remarks}

Finally, we point out that in almost all situations firms do not prefer to choose capacity simultaneously and then choose quantity simultaneously. This case has been studied by Nishimori and Ogawa (2004). Using their results ${ }^{6}$, we can calculate that social surplus and private firm's profit. The results are: $\mathrm{SS}=(1 / 2)\left(a-m_{b}\right)^{2}+(73 / 49)\left(m_{b}-m_{a}\right)^{2}$; and $\pi_{a}=$ $2\left(m_{b}-m_{a}\right)^{2}$. We check that the private firm's profit is strictly less than the corresponding expressions in all four cases considered here. Social surplus is strictly less than the corresponding expressions in Cases 1,3 and 4 . It is also less than in Case 2 when $(830 / 247)\left(m_{b}-m_{a}\right) \leq a-m_{b} \leq(22 / 3)\left(m_{b}-m_{a}\right)$ (Table 2).

In an environment of mixed oligopoly, Pal (1998) demonstrated that for two time periods all firms (including 1 public and $N \geqq 1$ private firms) producing simultaneously in the same time period cannot be sustained as a SPNE outcome. As far as the order of moves in a mixed oligopoly where the firms first choose the timing for choosing their capacities or quantities, our results are consistent with Pal's result. However, there is no study about endogenous order of moves in a mixed oligopoly where

\footnotetext{
${ }^{6}$ In Nishimori and Ogawa (2004), the public firm's capacity scale and quantity level are $x_{b}=a-2 m_{a}-3 m_{b}$ and $q_{b}=\left(a-2 m_{a}-3 m_{b}\right)+(1 / 7)\left(m_{b}-m_{a}\right)$, respectively. However, their calculation is not correct. The correct result should be $x_{b}=a+2 m_{a}-3 m_{b}$ and $q_{b}=\left(a+2 m_{a}-3 m_{b}\right)+(1 / 7)\left(m_{b}-m_{a}\right)$.
} 
Table 2

Social surplus and the private firm's profit

\begin{tabular}{lll}
\hline Case & Social surplus & Private firm's profit \\
\hline 1 & $(1 / 2)\left(a-m_{b}\right)^{2}+(102505 / 61009)\left(m_{b}-m_{a}\right)^{2}$ & $(235298 / 61009)\left(m_{b}-m_{a}\right)^{2}$ \\
2 & $(1 / 2)\left(a-m_{b}\right)^{2}+(1 / 784)\left[-93\left(a-m_{b}\right)^{2}+\right.$ & $(1 / 112)\left[\left(a-m_{b}\right)^{2}+124\left(a-m_{b}\right) \times\right.$ \\
& $\left.868\left(a-m_{b}\right)\left(m_{b}-m_{a}\right)-196\left(m_{b}-m_{a}\right)^{2}\right]$ & $\left.\left(m_{b}-m_{a}\right)-28\left(m_{b}-m_{a}\right)^{2}\right]$ \\
3 & $(1 / 2)\left(a-m_{b}\right)^{2}+(27967 / 15842)\left(m_{b}-m_{a}\right)^{2}$ & $(22304 / 7921)\left(m_{b}-m_{a}\right)^{2}$ \\
4 & $(1 / 2)\left(a-m_{b}\right)^{2}+(117 / 64)\left(m_{b}-m_{a}\right)^{2}$ & $(75 / 32)\left(m_{b}-m_{a}\right)^{2}$ \\
\hline
\end{tabular}

the firms first choose the timing for choosing their capacities before choosing other strategic variables. This is a direction for future research.

\section{Acknowledgements}

We thank the associate editor of the journal and an anonymous referee for very helpful comments.

\section{References}

Anderson, S., Palma, A., Thisse, J.F., 1997. Privatization and efficiency in a differentiated industry. European Economic Review 41, 1635-1654.

Basu, K., Singh, N., 1990. Entry deterrence in stackelberg perfect equilibria. International Economic Review 31, 61-71.

Bulow, J., Geanakopolos, J., Klemperer, P., 1985. Holding idle capacity to deter entry. Economic Journal 95, $178-182$.

Cremer, H., Marchand, M., Thisse, J.F., 1989. The public firm as an instrument for regulating an oligopolistic market. Oxford Economic Papers 41, 283-301.

De Fraja, G., Delbono, F., 1990. Game theoretic models of mixed oligopoly. Journal of Economic Surveys 4, 1-17.

Dixit, A., 1980. The role of investment in entry deterrence. Economic Journal 90, 95-106.

Horiba, Y., Tsutsui, S., 2000. International Duopoly, Tariff Policies and the Case of Free Trade Japanese Economic Review, vol. 512000 pp. 207-220.

Nett, L., 1993. Mixed oligopoly with homogeneous goods. Annals of Public and Cooperative Economics 64, 367-393.

Nishimori, A., Ogawa, H., 2004. Do Firms Always Choose Excess Capacity? Economics Bulletin, vol. 122004 pp. 1-7.

Pal, D., 1998. Endogenous timing in a mixed oligopoly. Economics Letters 61, 181-185.

Spence, A.M., 1977. Entry capacity, investment and oligopolistic pricing. Bell Journal of Economics 8, 534-544. Tirole, J., 1988. The Theory of Industrial Organization. MIT press, Cambrige.

Vives, X., 1986. Commitment flexibility, and market outcomes. International Journal of Industrial Organization 4, 217-229.

Ware, R., 1986. A model of public enterprise with entry. Canadian Journal of Economics 19, 642-655. 